\title{
Oral manifestations of gastrointestinal diseases
}

\author{
Tom D Daley DDS MSc FRCDC 1 , Jerrold E Armstrong DDS MSc FRCDC ${ }^{2}$
}

\begin{abstract}
TD Daley, JE Armstrong. Oral manifestations of gastrointestinal diseases. Can J Gastroenterol 2007;21(4):241-244.

The present paper offers a detailed review of the oral manifestations of various gastrointestional diseases or conditions, with suggestions on how they may be relevant to the practice of gastroenterology. The review includes Crohn's disease, ulcerative colitis, Gardner syndrome, Peutz-Jeghers syndrome, malabsorption conditions related to hematopoiesis, gastrointestinal malignancy metastatic to the jaws, jaundice and gastric reflux diseases.
\end{abstract}

Key Words: Gastrointestinal diseases; Oral manifestations
T esions within the jaws, oral mucosa or perioral tissues may Lsometimes be seen as manifestations of gastrointestinal (GI) diseases. The oral lesions may occasionally occur before the onset of GI disease, be present during the disease process or persist even after the disease has resolved. Sometimes the oral lesions are similar to GI lesions, while at other times, the oral changes are caused by systemic alterations secondary to GI disease, such as those related to malabsorption. The present paper reviews and illustrates the oral changes observed in selected GI diseases.

\section{IDIOPATHIC INFLAMMATORY BOWEL DISEASE}

As is the case with bowel diseases (1), the clinical distinction between the oral manifestations of Crohn's disease and ulcerative colitis may be blurred with overlapping clinical features. Nonspecific clinical changes such as dry mouth, halitosis and gastric reflux are seen (2), but these are neither diagnostic nor helpful in the differentiation of the two conditions. The microscopic presence of granulomas is considered diagnostic of oral Crohn's disease in the appropriate clinical setting, whereas microabcesses of neutrophils and eosinophils without granulomas is considered consistent with ulcerative colitis in the appropriate clinical setting.

\section{Crohn's disease}

Dupuy et al (3) found that only $0.5 \%$ of their patients with Crohn's disease developed oral lesions, and these patients were more likely to also have anal and esophageal lesions. There is a predilection for males and onset in youth. Occasionally, the oral manifestations may be the first indication that a patient has Crohn's disease, but the oral lesions usually develop in patients with known bowel disease. The oral lesions are multifocal, linear, nodular, polypoid or diffuse mucosal thickenings, with a predilection for occurring in the labial and buccal mucosa, and the mucobuccal folds (Figure 1). They are characteristically firm, pink and painless to palpation unless there are ulcerations that may cause pain on touch, or when eating acidic, spicy or hot foods. These ulcers, which are typically persistent, linear and deep (3), should not be confused with aphthous ulcers, which are shallow, round to oval shaped lesions that heal spontaneously in approximately seven to 14 days (4). On

\section{Manifestations orales des maladies digestives}

Le présent article offre une revue détaillée des manifestations orales de diverses maladies ou affections de l'appareil digestif et fait état de leur pertinence relative en gastro-entérologie. Il porte entre autres sur la maladie de Crohn, la colite ulcéreuse, le syndrome de Gardner, le syndrome de Peutz-Jeghers, les syndromes de malabsorption liés à l'hématopoièse, les cancers de l'appareil digestif avec métastase de la mâchoire, l'ictère et les maladies associées au reflux gastrique. palpation, the lesions may feel granular below the epithelium, reflecting the histological findings.

Microscopically, the lesions exhibit subepithelial, noncaseating granulomatous inflammation characterized by epithelioid histiocytes, giant cells and lymphocytes (Figure 2), identical to those seen in the bowel. There is great variability in the severity of the inflammation, which is worse if ulcers are present. Oral lesions are routinely subjected to special histochemical stains to rule out infectious agents such as deep fungal infections or tuberculosis, and polarized to rule out foreign body reactions. Because granulomatous microscopic lesions are seen in other diseases, including orofacial granulomatosis and sarcoid (4), the definitive diagnosis of Crohn's disease cannot be made on oral biopsy alone. However, the biopsy may direct the clinician to investigate the GI tract for Crohn's disease lesions.

Oral lesions of Crohn's disease are typically persistent, and remit and relapse over the years (3). Their response to systemic therapy is highly variable and unpredictable, and they do not necessarily parallel the activity of gut disease. Some oral ulcerating lesions may require topical corticosteroid therapy or even intralesional corticosteroid injections. Dupuy et al (3) reported two cases in which intraoral adhesions developed.

\section{Ulcerative colitis}

Oral lesions of ulcerative colitis - termed pyostomatitis vegetans $(5,6)$ - are rare, and are far less common than oral manifestations of Crohn's disease. There is a male predilection (5), and oral outbreaks may occur at any age (6). The oral lesions may precede GI lesions but are generally present synchronously. Clinically, the lesions consist of scattered, clumped or linearly oriented pustules on an erythematous mucosa at multiple oral sites, with variable severity (Figure 3), but usually sparing the dorsum of the tongue. Patient discomfort is proportional to the degree of ulceration of the lesions, many of which remain epithelialized. Long-standing lesions may become granular, polypoid or fissured (6), clinically mimicking Crohn's disease. Some patients exhibit oral aphthous-like lesions (6) in addition to the pustular lesions, and approximately $10 \%$ of patients develop inflammatory bowel disease-associated arthritis of the temporomandibular joints (6).

${ }^{1}$ Division of Oral Pathology, Department of Pathology, University of Western Ontario; ${ }^{2}$ London Health Sciences Centre, London, Ontario

Correspondence: Dr Tom Daley, Department of Pathology, University of Western Ontario, London, Ontario N6A 5C1.

Telephone 519-661-2111 ext 86405, fax 519-850-2926, e-mail tdaley@schulich.uwo.ca

Received for publication July 19, 2006. Accepted July 20, 2006 


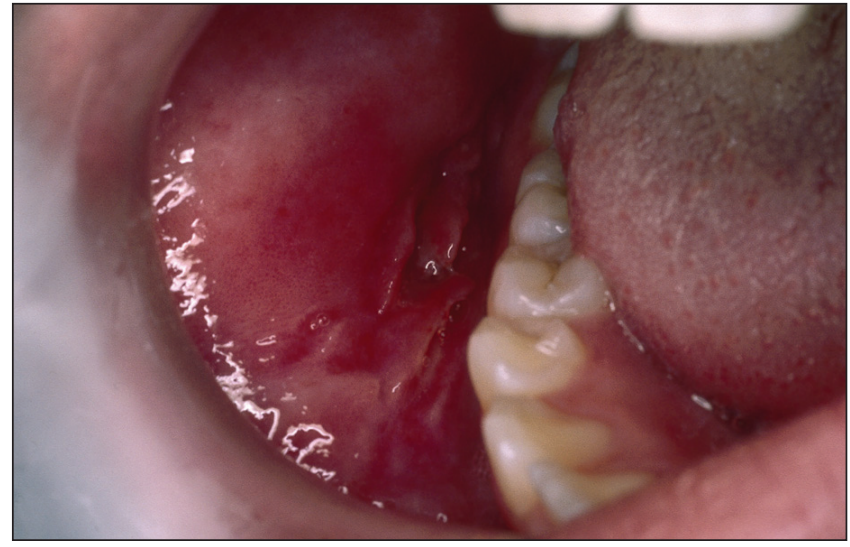

Figure 1) Adolescent male patient with diagnosed Crohn's disease of the bowel exhibiting nodular submucosal lesions of the left and right buccal mucosa

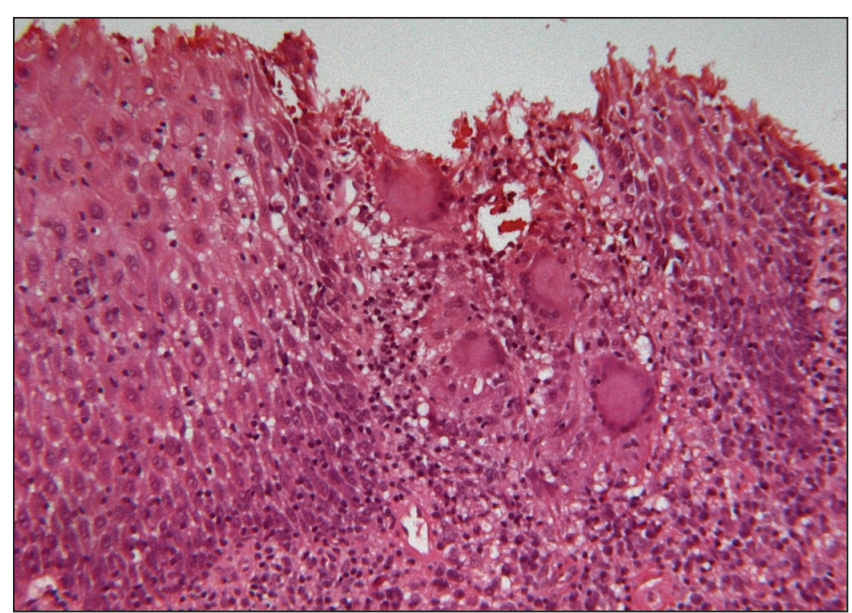

Figure 2) Oral Crohn's disease exhibiting granulomatous inflammation similar to that seen in the bowel. There is ulceration of the overlying epithelium in a biopsy of a painful lesion of the mandibular mucobuccal fold (hematoxylin and eosin stain, original magnification $\times 100$ )

Microscopically, the lesions mimic the crypt abscesses of colonic lesions, without evidence of granulomatous inflammation. The oral submucosa shows edema with neutrophils, eosinophils and lymphocytes, while the epithelium shows spongiosis with neutrophilic and eosinophilic abscesses (5) (Figure 4). The microscopic appearance in itself is not diagnostic, because neutrophilic or eosinophilic intraepithelial abscesses may be seen in other conditions such as candidiasis, benign migratory glossitis, or stomatitis areata migrans and pemphigus vegetans (4). The clinical appearance and historical information must be correlated with the microscopic findings; otherwise, asymptomatic patients who receive an oral diagnosis of pyostomatitis vegetans should be investigated by a gastroenterologist for bowel disease (5).

The oral lesions usually respond to colonic disease treatment (6). Topical or systemic corticosteroids (5) and dapsone (6) have been used for recalcitrant oral lesions with variable effectiveness.

Because the severity of oral disease usually reflects the severity of the bowel disease, the gasteroenterologist may use oral manifestations, when present, as an additional gauge to determine the severity of the bowel disease and/or the response to therapy.

\section{GARDNER SYNDROME}

A genetic defect on chromosome 5 leads to this autosomal dominant (or sporadic mutation) disease characterized by intestinal

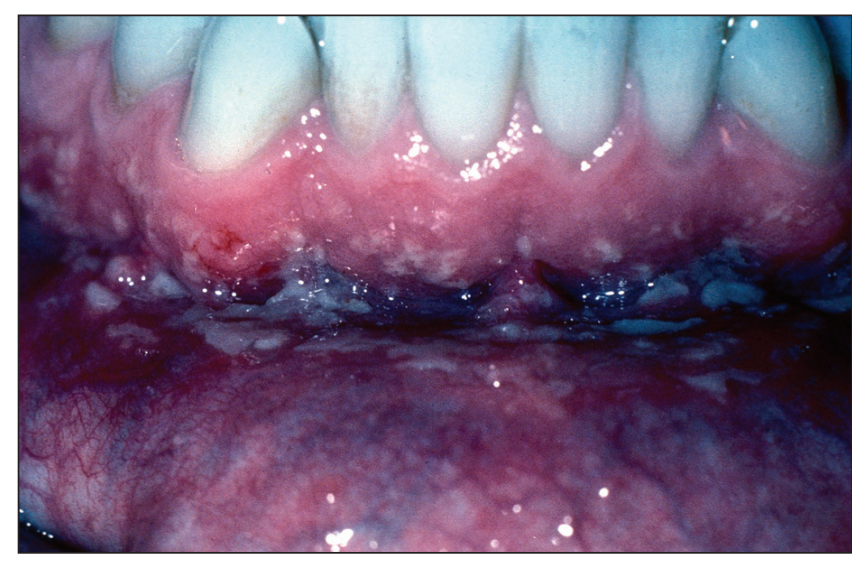

Figure 3) Oral lesions in ulcerative colitis showing tiny yellow pustules on the oral mucosa, reflecting the microabscesses seen microscopically

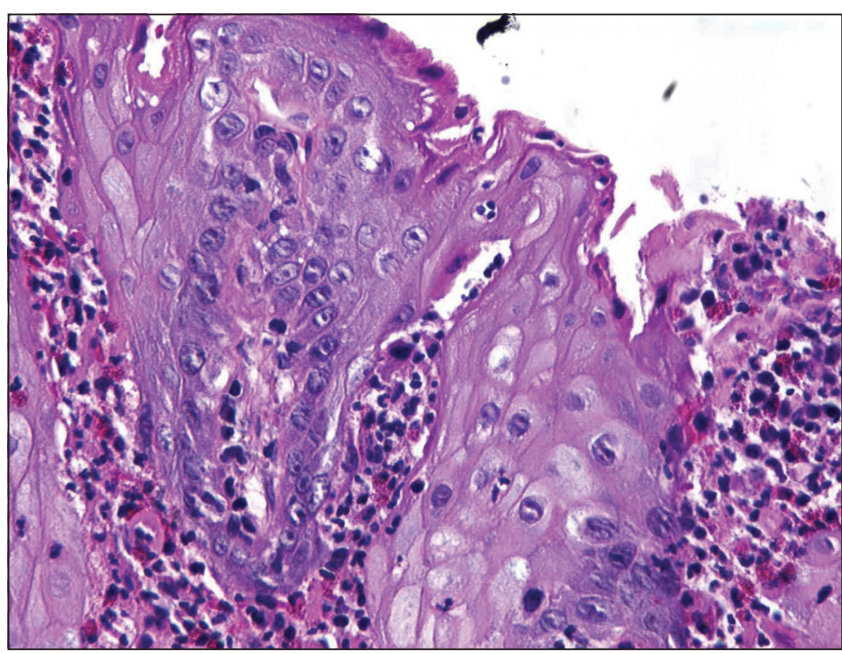

Figure 4) The microscopic appearance of oral lesions in ulcerative colitis showing neutrophilic and eosinophilic abcesses, spongiosis with subepithelial mixed inflammation and edema (hematoxylin and eosin stain, original magnification $\times 250$ )

polyposis with a very high risk of malignant transformation into colonic adenocarcinoma (1). It is associated with a number of extracolonic changes involving a variety of organ systems, including the skin, skeleton and soft tissues (4). Potential head and neck manifestations, most of which begin in childhood or adolescence, are (7) (Figure 5):

- multiple enostoses of the jaws;

- supernumary and/or unerupted teeth;

- increased risk of odontomas;

- osteomas of the jaws and paranasal sinuses; and,

- epidermoid cysts of the skin of the head and neck.

The enostoses are frequently seen radiographically in the alveolar portions of the jaws without evidence of bone expansion. They are completely asymptomatic. The supernumary and unerupted teeth occur in the incisor, cuspid and bicuspid regions, while the molar areas are rarely affected. Supernumary teeth are usually peg shaped or otherwise misshapen. The odontomas are the compound type and occur in the same distribution as the supernumary teeth. The osteomas, which cause a focal expansion of the surface of the jaw bone, can be felt through the skin or oral mucosa and may be large enough to be clinically visible (7).

The osteomas and epidermoid cysts are removed surgically if they are large enough to cause functional or cosmetic problems. 

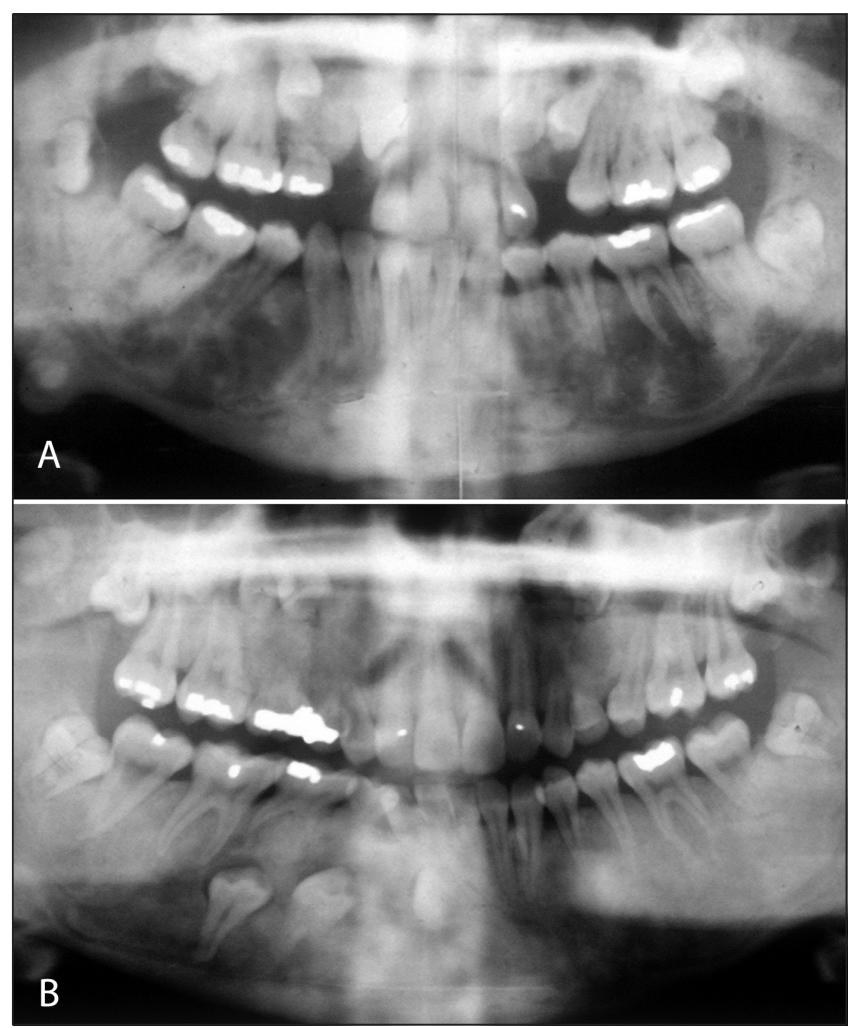

Figure 5) Radiographs of two sisters with Gardner syndrome showing enostoses, unerupted teeth and osteomas of the mandible

Asymptomatic impacted teeth may be left in place in the jaws if there is no clinical indication to remove them. However, it may be necessary to remove one or more of these additional teeth for orthodontic and/or occlusion considerations, or for cosmetic reasons in some cases. The odontomas are usually surgically curetted.

The oral manifestations may be used by the gastroenterologist to help to identify the syndrome clinically and at an early age, so that appropriate screening for bowel polyposis and adenocarcinoma may be undertaken. Ida et al (7) suggested that patients with three to six osteomatous lesions of the jaw should be questioned about the possibility of Gardner syndrome, and patients with more than six lesions should be regarded as affected until proven otherwise.

\section{PEUTZ-JEGHERS SYNDROME}

A mutation of the LKB1 gene has been found for patients with Peutz-Jeghers syndrome (4). This condition, which is associated with hamartomatous polyposis, mostly of the small intestine, is autosomal dominantly inherited or a result of spontaneous mutation (1).

Orally, the significant change is in perioral and/or oral pigmentation, which develops in childhood $(8,9)$. Nonsundependent freckling of the skin around the lips and the vermilion zone of the lips is a common feature (9). Intraorally, the lesions are usually flat, painless, brown pigmented patches of the buccal mucosa, tongue or labial mucosa $(4,8)$. Microscopically, these lesions show mild acanthosis with elongation of rete pegs, and increased pigmentation in the melanocytes and the adjacent keratinocytes (8). There is no increase in the melanocyte number.

No treatment is required for the pigmented lesions unless there are cosmetic or social reasons to treat. Zaheri et al (8) reported good results with the use of potassium-titanyl-phosphate laser ablation.

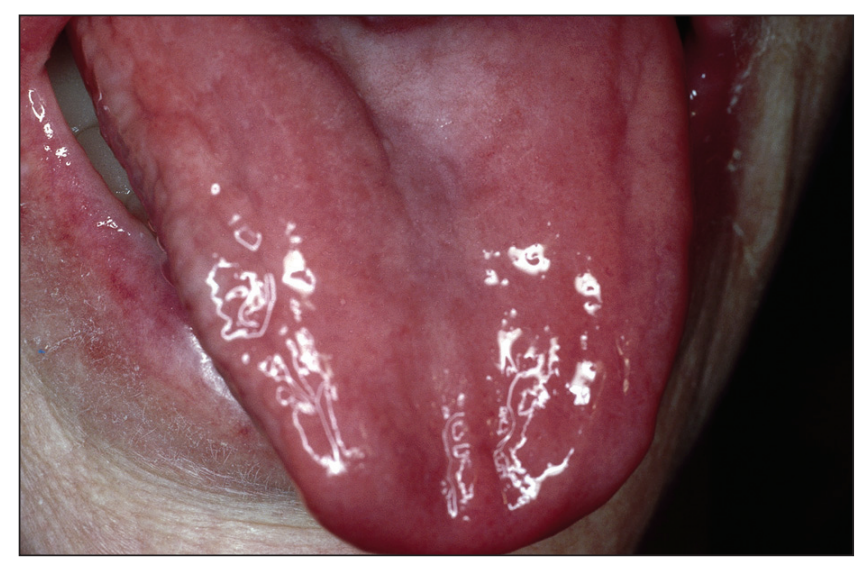

Figure 6) Patient with a sore, bald, red tongue (atrophic glossitis) associated with iron deficiency anemia

As in Gardner syndrome, the oral manifestations are important in contributing to the identification of the condition at an early age to allow for appropriate screening for bowel disease and other neoplasms.

\section{MALABSORPTION CONDITIONS AFFECTING HEMATOPOIESIS}

GI diseases related to protein-caloric malnutrition (10) or micronutrient malabsorption (11) may have an effect on the oral tissues. The classical examples are iron malabsorption inducing iron deficiency anemia and vitamin $\mathrm{B}_{12}$ malabsorption in pernicious anemia (12). When the malabsorption is sufficiently severe, the first oral manifestation is atrophic glossitis (Figure 6), in which the filiform papilla and sometimes the fungiform papilla of the dorsum of the tongue undergo atrophy, leaving a bald, red tongue (4). In milder cases, the atrophy is patchy, but more severe cases show involvement of the entire dorsum. In very severe cases, there may be shallow, round to oval-shaped, persistent ulcers with bright red borders, clinically resembling aphthous ulcers but often responsive to appropriate replacement therapy. Overt tongue lesions are usually sore, but a more common complaint is a burning sensation (glossopyrosis) that may precede clinically detectable oral lesions (12). Other oral mucosa may also become involved with atrophic zones, with or without aphthous-like ulcers and the burning sensation, but these lesions are not as dramatic as the bald tongue and often go unnoticed. Affected patients are predisposed to developing angular cheilitis, which is a candidal infection that can be treated with antifungal medication.

The gastroenterologist may use atrophic glossitis as an indicator of moderate to severe nutrient malabsorption.

\section{METASTATIC DISEASE TO THE JAWS}

Malignant neoplasms of the liver and GI tract occasionally metastasize to the oral region, most commonly to the posterior mandible and usually through the hematogenous route (Figure 7). The vertebral plexus of veins is considered the primary mechanism whereby these tumours bypass the right heart-lung capillary bed. Patients with mandibular metastases may be asymptomatic, or may complain of jaw or tooth pain, paresthesia (unilateral or bilateral numbness of the chin) or loosening of teeth (4). Initially, the neoplasm is sometimes found in a nonhealing extraction socket after a tooth has been extracted because of unexplained looseness. Radiographs may show irregular, poorly circumscribed and often multifocal radiolucencies. Less commonly, metastases may involve the maxilla or oral soft tissues (13). 


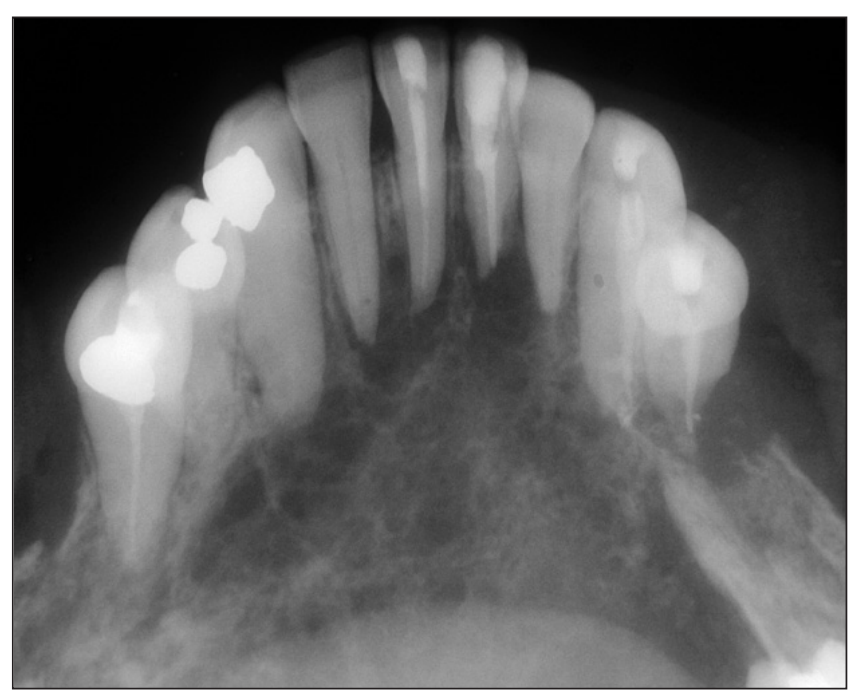

Figure 7) Radiograph showing radiolucent, multifocal adenocarcinoma metastatic to the mandible

GI metastatic disease to the oral region is a grave prognostic sign, usually indicating widespread metastases (13). Few patients survive five years; most die within one year (4).

\section{JAUNDICE}

Excess bilirubin in the blood results in the accumulation of bilirubin in tissues, including the oral mucosa, inducing a yellow discolouration (1). The severity of the yellow discolouration depends on the blood concentration of bilirubin and the duration of the problem. Because bilirubin has an affinity for elastin, the mobile oral tissues with higher elastic content, such as the lingual frenum and the soft palate, are more severely affected (4). A yellowish to greenish pigmentation (biliverdin deposition) occurs in the teeth of children with hyperbilirubinemia during calcification, as may be seen in the primary teeth of biliary atresia patients. This is not seen in adults who develop liver disease after the enamel on the teeth has already calcified.

Gastroenterologists may examine the oral tissues to help in the clinical assessment of the extent of jaundice. However, care should be taken in assessing a yellowish discolouration of the soft palate in patients receiving or eating large amounts of vitamin $\mathrm{A}$, which is stored in the fat of the soft palate.

\section{GASTRIC REFLUX}

Enamel erosion by gastric acids may be seen in patients with chronic gastric reflux conditions such as gastroesophageal reflux disease $(14,15)$, hiatus hernia, wine drinking, chronic alcoholism and bulimia (16). Clinically, the enamel is lost over broad areas of the teeth that are exposed to the gastric contents. In bulimics, it is commonly seen and is most severe on the inner surface of the maxillary anterior teeth (Figure 8). The eroded enamel is smooth, shiny and hard. If it becomes thin enough, the yellowish colour of the dentin becomes visible and the teeth may become sensitive to temperature changes. Once the enamel has eroded, it is not replaceable physiologically and the patient may require dental restorative treatment.

Because enamel erosion is directly proportional to the contact time with gastric acid, the gastroenterologist may get some idea of the frequency and duration of the reflux problem by assessing the amount of enamel loss. The patient's dentist may be helpful in this determination if dental records are available.

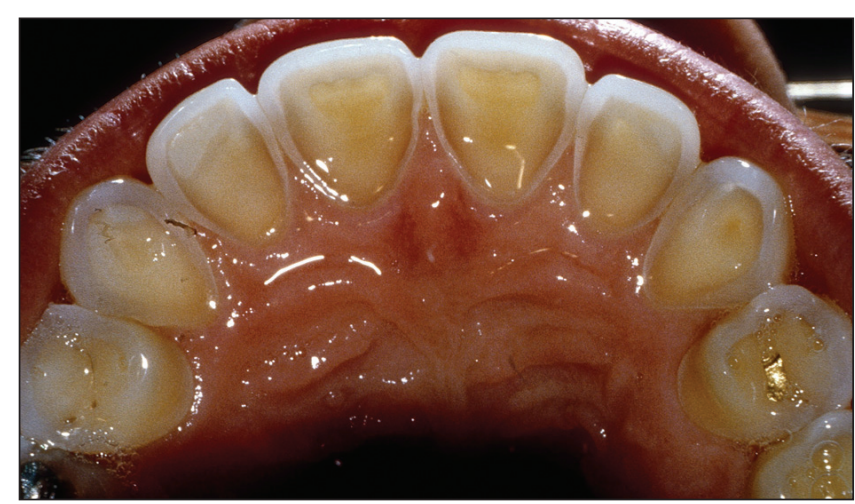

Figure 8) The palatal surface of the maxillary anterior teeth of a bulimic patient showing dissolved enamel due to erosion

\section{SUMMARY}

Oral manifestations of GI diseases may be useful to the gastroenterologist in the development of a differential diagnosis for patients with GI complaints, and oral tissues may offer an easy biopsy site to diagnose conditions such as Crohn's disease. In other circumstances, the severity or prognosis of the disease can be monitored by the presence or extent of oral manifestations, and the success of the management of GI diseases may be reflected in the response of oral tissues.

\section{REFERENCES}

1. Kumar V, Fausto N, Abbas A. Robbins and Cotran's Pathologic Basis of Disease, 7th edn. Philadelphia: Elsevier Saunders, 2005.

2. Katz J, Shenkman A, Stavropoulos F, Melzer E. Oral signs and symptoms in relation to disease activity and site of involvement in patients with inflammatory bowel disease. Oral Dis 2003:9:34-40.

3. Dupuy A, Cosnes J, Revuz J, Delchier JC, Gendre JP, Cosnes A. Oral Crohn disease: Clinical characteristics and long-term follow-up of 9 cases. Arch Dermatol 1999;135:439-42

4. Neville BW, Damm DD, Allen CM, Bouquot JE. Oral \& Maxillofacial Pathology, 2nd edn. Philadelphia: WB Saunders, 2002.

5. Chaudhry SI, Philpot NS, Odell EW, Challacombe SJ, Shirlaw PJ. Pyostomatitis vegetans associated with asymptomatic ulcerative colitis: A case report. Oral Surg Oral Med Oral Pathol Oral Radiol Endod 1999;87:327-30.

6. Ruiz-Roca JA, Berini-Aytes L, Gay-Escoda C. Pyostomatitis vegetans Report of two cases and review of the literature. Oral Surg Oral Med Oral Pathol Oral Radiol Endod 2005;99:447-54.

7. Ida M, Nakamura T, Utsunomiya J. Osteomatous changes and tooth abnormalities found in the jaws of patients with adenomatosis coli. Oral Surg Oral Med Oral Pathol 1981;52:2-11.

8. Zaheri S, Chong SK, Harland CC. Treatment of mucocutaneous pigmentation in Peutz-Jeghers syndrome with potassium titanyl phosphate (KTP) laser. Clin Exp Dermatol 2005;30:710-2.

9. Gavren BA, Lumerman H, Cardo VA, Schmidt BL. Multiple pigmented lesions of the lower lip. J Oral Maxillofac Surg 2002;60:438-45.

10. Bohmer T, Mowe M. The association between atrophic glossitis and protein-calorie malnutrition in old age. Age Ageing 2000;29:47-50.

11. Drinka PJ, Langer E, Scott L, Morrow F. Laboratory measurements of nutritional status as correlates of atrophic glossitis. J Gen Intern Med 1991;6:137-40.

12. Field EA, Speechley JA, Rugman FR, Varga E, Tyldesley WR. Oral signs and symptoms in patients with undiagnosed B12 deficiency. J Oral Pathol Med 1995;24:468-70.

13. van der Waal RI, Buter J, van der Waal I. Oral metastatases: Report of 24 cases. Br J Oral Maxillofac Surg 2003;41:3-6.

14. Moazzez R, Bartlett D, Anggiansah A. Dental erosion, gastrooesophageal reflux disease and saliva: How are they related? J Dent 2004;32:489-94.

15. Barron RP, Carmichael RP, Marcon MA, Sandor GK. Dental erosion in gastroesophageal reflux disease. J Can Dent Assoc 2003;69:84-9.

16. Little JW. Eating disorders: Dental implications. Oral Surg Oral Med Oral Pathol Oral Radiol Endod 2002;93:138-43. 


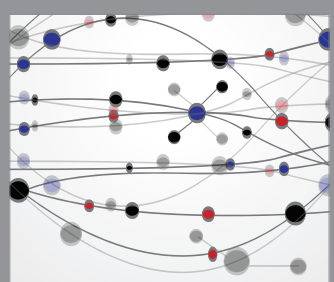

The Scientific World Journal
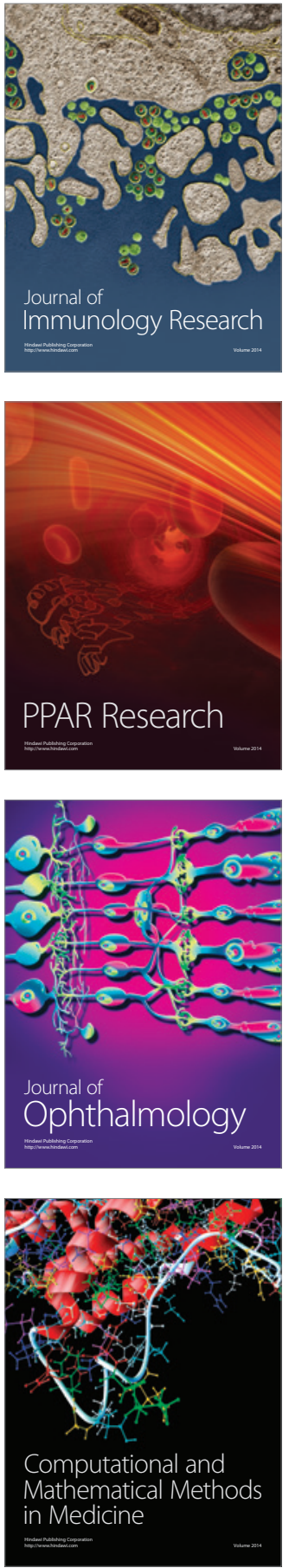

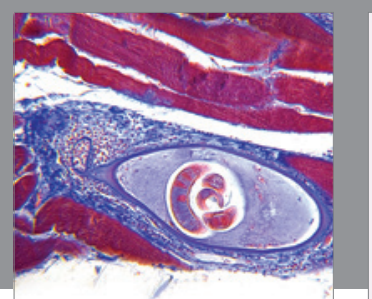

Gastroenterology Research and Practice

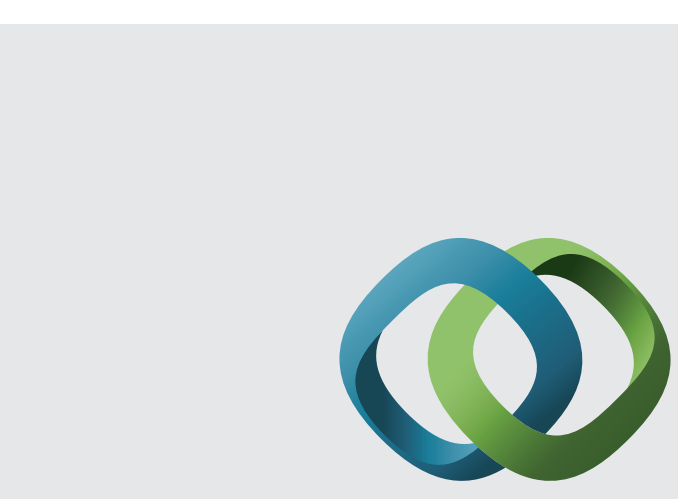

\section{Hindawi}

Submit your manuscripts at

http://www.hindawi.com
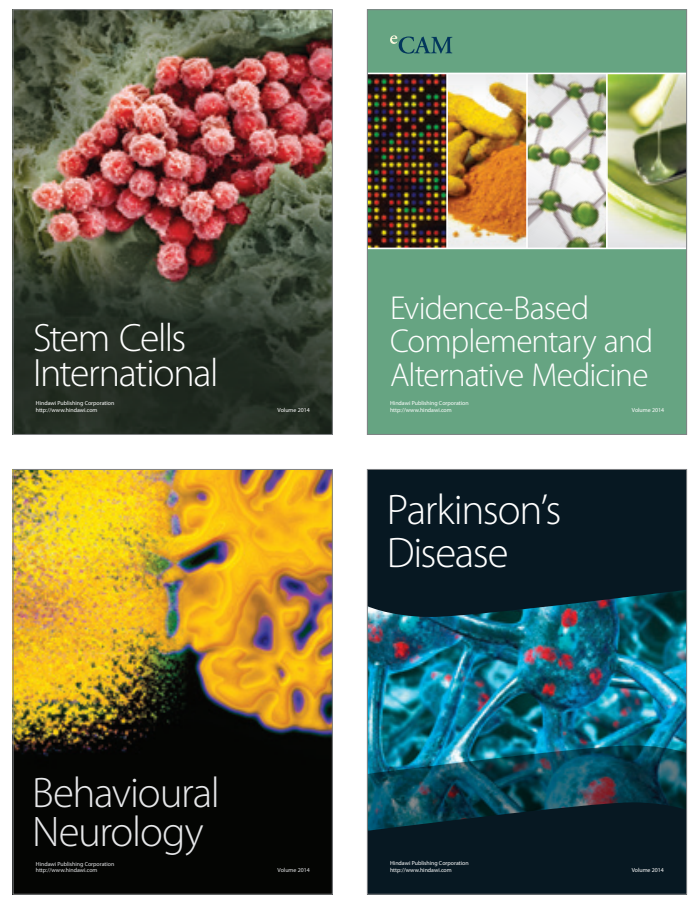
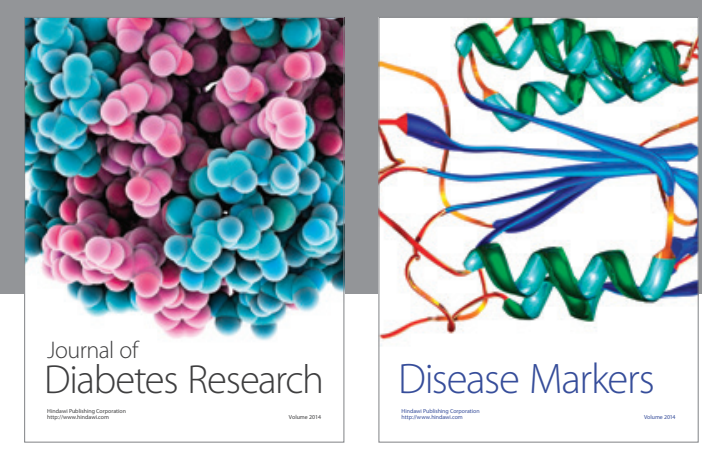

Disease Markers
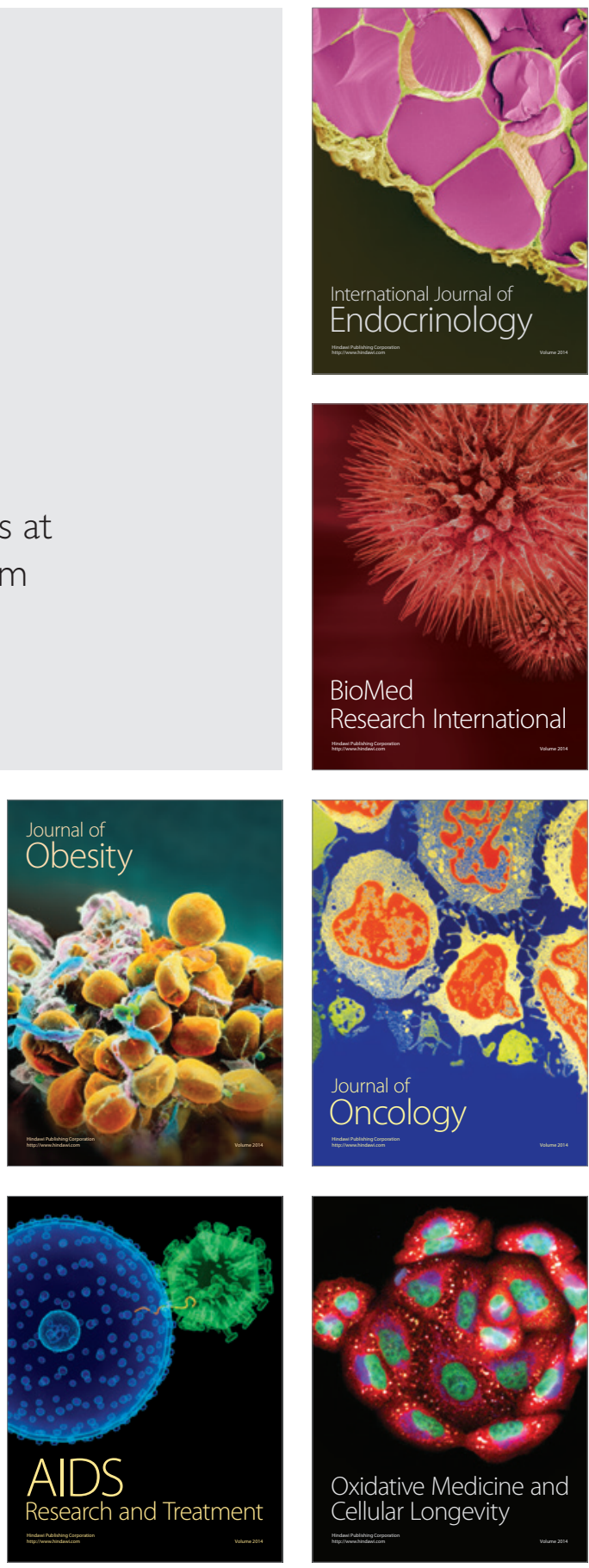